\title{
Vigor and mortality of citrus progenies with potential use as rootstocks
}

\author{
Lizziane Gomes Leal Santana ${ }^{1}$, Edson dos Santos Souza ${ }^{1}$, Orlando Sampaio Passos², Abelmon da Silva Gesteira², Carlos Alberto da \\ Silva Ledo², Walter dos Santos Soares Filho²*
}

1Federal University of Recôncavo da Bahia/Center of Agrarian, Environmental and Biological Sciences, R. Rui Barbosa, 710 - 44380-000 - Cruz das Almas, BA - Brazil. ${ }^{2}$ Embrapa Cassava \& Fruits, R. Embrapa, s/n - 44380-000 Cruz das Almas, BA - Brazil.

*Corresponding author <walter.soares@embrapa.br>

Edited by: Roberto Fritsche Neto

Received December 16, 2016

Accepted April 26, 2017
ABSTRACT: Rootstocks influence certain characteristics of the scion, such as vigor, fruit yield and quality, and tolerance to biotic and abiotic factors. In conventional citrus breeding programs, hybridization is the main method used for obtaining rootstock varieties. Between Sept and Oct 2006, controlled pollinations were carried out resulting in nine progenies, totaling 461 hybrid seedlings. The female parents were the 'Santa Cruz Rangpur' lime (SCRL) and the 'Sunki of Florida' mandarin (SFM), while the male parents, in addition to this mandarin, were the 'Indio' and 'Riverside' citrandarins, the 'Thomasville' citrangequat (THOM), the 'Swingle' citrumelo, the 'Argentina' citrange (AGC) and the 'Benecke' trifoliate orange (BKTO). Fruit setting rates of these crosses were measured and the hybrids generated were planted in the field in 2008 and evaluated from 2010 to 2014 , for the variables of plant mortality, visual vigor, plant height and trunk diameter. The descriptive statistics mean, variation range, coefficient of variation and Pearson skewness coefficient were calculated. Data were submitted to analysis of variance and the means of the treatments were grouped by the Scott-Knott test, both at $5 \%$ significance. The progenies, having the 'Sunki' mandarin as the female parent, presented higher fruit setting rates and lower plant mortality rates than those obtained from the female parent 'Rangpur' lime, while zero plant mortality was observed in the SFM $\times$ BKTO cross. The crosses SCRL $\times$ SFM, SFM $\times$ BKTO, SFM $\times$ AGC and SFM $\times$ THOM have the potential to generate vigorous hybrids, resulting in rootstock varieties adapted to the landscape unit of Coastal Tableland.

Keywords: Citrus spp., Poncirus trifoliata, hybridization, plant breeding

\section{Introduction}

Brazil is the world's leading country in the production of sweet oranges [Citrus sinensis (L.) Osbeck], with yearly output of 18 billion metric tons, followed by the United States with 8 billion tons and China with 7 billion tons (FAO, 2016). The expansion of the crop, however, has been limited by the occurrence of various diseases, a situation aggravated by the predominance of the 'Rangpur' lime (C. limonia Osbeck) as the rootstock of most citrus orchards, rendering the Brazilian Citrus Industry vulnerable (Fundecitrus, 2014). It is therefore necessary to diversify the rootstock varieties suitable for growing in the country's various regions.

The Citrus Breeding Program of Embrapa Cassava \& Fruits (CBP) has been conducting controlled hybridization studies since Sept 1988 with the aim of producing new varieties, notably rootstock, adapted to the different Brazilian geographic regions, in particular the northeastern region. Its main focus is to develop rootstock varieties that are both tolerant to drought and resistant to phytophthora gummosis and the Citrus tristeza virus complex (CTV). In addition to these factors, it is fundamental that the rootstocks selected be easy to propagate, i.e., their fruits should have a large number of seeds. These seeds should have high polyembryony expression and a satisfactory germination rate, with the resulting nucellar plants (individuals that are genetically identical to the mother plant) having good vigor and compatibility with the main scion varieties, enabling good yield of high-quality fruits from long-lived trees (Khan and
Kender, 2007; Zekri, 2011). The process of developing hybrid rootstock varieties by the CBP includes three basic steps: (1) obtaining hybrid populations; (2) field evaluation of seedlings of the hybrids generated; and (3) selection of the best individuals and evaluation of these as rootstocks in combination with various scion varieties during a series of harvests.

This article reports on the progress made in the first two basic steps of obtaining hybrid rootstocks by the CBP. The aim of these steps was to identify the crosses able to generate progenies that are best suited for the selection of individuals with high potential for adaptating to the environment in the area where the program is being conducted, the landscape unit of Coastal Tableland, where most citrus growing occurs in Bahia and Sergipe, the main citrus producing states in northeastern Brazil. Another objective was to identify the parental varieties that, through interspecific or intergeneric crosses, have high potential to obtain good rootstocks. For this purpose, the citrus progenies were analyzed considering fruit setting from the pollinations carried out, visual vigor, plant height, trunk diameter, and plant mortality rate of the hybrid seedlings obtained, in order to verify their potential for generating suitable rootstock varieties.

\section{Materials and Methods}

The CBP was conducted at the headquarters of Embrapa Cassava \& Fruits, located in the municipality of Cruz das Almas, in the Recôncavo Baiano region of 
Bahia (representative of the Coastal Tableland), at coordinates $12^{\circ} 40^{\prime} 19^{\prime \prime}$ South latitude and $39^{\circ} 06^{\prime} 23^{\prime \prime}$ West longitude, and altitude of $226 \mathrm{~m}$. Yearly rainfall ranges from $1,000 \mathrm{~mm}$ to $1,200 \mathrm{~mm}$, falling for 8 to 10 months, with dry spells occurring in 2 to 6 months. Most citrus orchards in this region are not irrigated.

Controlled pollinations started in Sept 2006, using accessions from the Citrus Active Germplasm Bank of Embrapa Cassava \& Fruits (CAGB). The female parents employed were the 'Santa Cruz Rangpur' lime (SCRL) and the 'Sunki of Florida' (SFM) mandarin [C. sunki (Hayata) hort. ex Tanaka], while the male parents were, in addition to the mandarin, the 'Indio' (IDC) and 'Riverside' (RSC) citrandarins [common 'Sunki' mandarin $\times$ Poncirus tritoliata (L.) Raf. 'English' selection], the 'Thomasville' (THOM) citrangequat [kumquat 'Oval' or 'Nagami' Fortunella margarita (Lour.) Swingle $\times$ 'Willits' citrange $(C$. sinensis $\times P$. trifoliata) $]$, the 'Swingle' (SWC) citrumelo (C. paradisi Macfad. $\times P$. trifoliata), the 'Argentina' (AGC) citrange and the 'Benecke' (BKTO) trifoliate orange $P$. trifoliata. Nine progenies were obtained, consisting of 461 hybrid seedlings.

The number of controlled pollinations varied among the crosses, in function of the availability of flowers at the moment of performing them. Considering the female parent 'Santa Cruz Rangpur' lime, 27 pollinations were carried out with the 'Sunki of Florida' mandarin, 42 with the 'Indio' citrandarin, 20 with the 'Riverside' citrandarin and 36 with the 'Thomasville' citrangequat, while when the female parent was the 'Sunki of Florida' mandarin, the number of pollinations were 68 with the 'Swingle' citrumelo, 39 with the 'Argentina' citrange, 14 with the 'Benecke' trifoliate orange, 23 with the 'Thomasville' citrangequat and 12 with the 'Indio' citrandarin, making a total of 281 pollinations.
Pollen grains collected from recently opened flowers of the male parents were used to pollinate the flowers of the female parents. The latter were emasculated before anthesis. The emasculation was performed at the balloon stage (just before the floral opening), by carefully eliminating the petals and anthers with tweezers and scalpel, avoiding contact with the stigma. The pollination was carried out immediately after emasculation, while the stigma was receptive (moist).

Four to five months after the pollinations, the resulting fruits were harvested and the fruit setting rate was calculated in relation to the pollinations performed: (number of fruits / number of pollinations) $\times 100$. The fruits were washed with running water, the seeds removed, then rewashed to remove the mucilage and placed out to dry in the shade at room temperature for 2 days. After drying, they were treated with a specific fungicide for this purpose and planted in Styrofoam trays in a greenhouse.

The identification of the hybrid seedlings obtained from the controlled crosses, to separate them from those of nucellar origin, was based on morphological traits, mainly those related to the leaves, particularly the dominant trifoliate trait present in $P$. trifoliata and in hybrids of this species (Soost and Cameron, 1975; Oliveira, 2002).

The progenies were transplanted to the field in 2008, after conventional soil preparation by plowing and harrowing. No subsoiling, $\mathrm{pH}$ correction or base fertilization was performed. The treatment after planting consisted of weeding around the trees and control of ants as necessary. Topdressing was applied starting in 2011 with NPK, in conformity with the soil analysis results. From 2010 to 2014, the following factors were determined: visual vigor, on a scale of 1 to 3 (Figures $1 \mathrm{~A}, \mathrm{~B}$, and C); plant height, measured from the surface

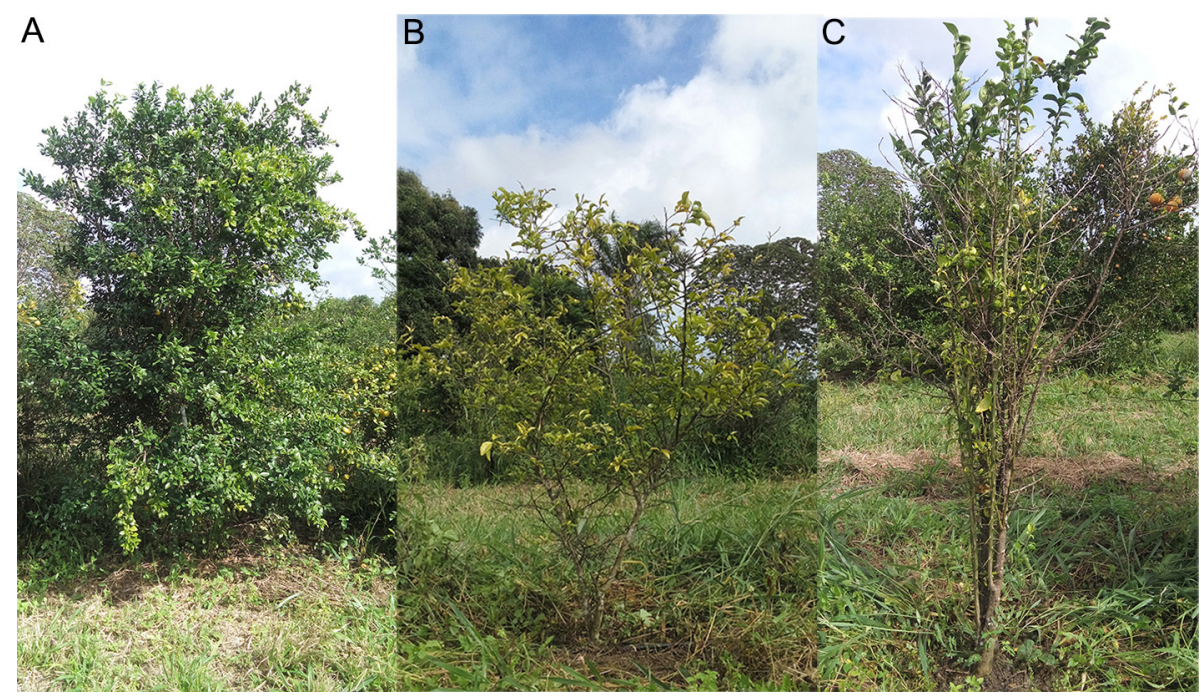

Figure 1 - Visual vigor scale, considering as vigorous those plants, regardless of size, containing plentiful leaves without signs of nutritional deficiency or disease symptoms: A) good vigor; B) medium vigor; and C) poor vigor. 
of the soil to the top of the plant, with a measuring rod (in $\mathrm{m}$ ); and trunk diameter, measured $10 \mathrm{~cm}$ above the transition between root and trunk, with a caliper rule (in $\mathrm{cm}$ ). In 2014 the plant mortality rate of the progenies was determined as a percentage: (number of live plants / number of original plants) $\times 100$.

The growth of the hybrid seedlings in the progenies was estimated by the geometric method. The geometric growth rate $(\mathrm{r})$ is calculated by subtracting 1 from the $n$-th root of the quotient between the final population (number of plants in progenies, $\mathrm{Pt}$ ) and the population at the start of the period considered (P0), multiplied by 100 , where " $n$ " is the number of years in the period (IBGE, 2004).

The descriptive statistics calculated were: mean $(\bar{X})_{\text {; }}$ variation range $(\mathrm{R})$, corresponding to the interval between the minimum and maximum values observed; the coefficient of variation $(\mathrm{CV})$, given by

$C V=\frac{\text { standard deviation }}{\text { mean }} 100$;

and the Pearson skewness coefficient (AS), given by

$A S=\frac{3 \text { (mean }- \text { median })}{\text { standard deviation }}$

The data were also submitted to analysis of variance (Ftest) and the means were grouped by the Scott-Knott test (Scott and Knott, 1974) at $5 \%$ significance. The classification ranges of the coefficients of variation were based on the method proposed by Garcia (1989), which uses the relationship between the mean of the coefficients of variation $(\mathrm{CV})$ and the standard deviation (s), as follows: low $(C V \leq \bar{X} \leq s)$, medium $(\bar{X}-s<C V \leq \bar{X}+s)$, high $(\bar{X}$ $+s<C V \leq \bar{X}+2 s)$ and very high $(C V>\bar{X}+2 s)$. The statistical analyses were carried out using the $\mathrm{R}$ statistical package (R Core Team v. 3.1.2).

\section{Results and Discussion}

With respect to the fruit setting rate, for the female parent 'Santa Cruz Rangpur' lime the highest value obtained (48\%) was for the cross with the 'Sunki of Florida' mandarin as the male parent. With regard to this mandarin variety, used as the female parent, the highest fruit setting rate $(82 \%)$ was with the 'Argentina' citrange as the male parent. Among the male parents employed, the 'Indio' citrandarin and the 'Thomasville' citrangequat were used for crosses both with the 'Santa Cruz Rangpur' lime and the 'Sunki of Florida' mandarin, and the fruit setting rates with the latter were twice as high as those with the former. In general terms, in comparison with the female parents, the 'Sunki of Florida' mandarin was superior to the 'Santa Cruz Rangpur' lime, since high setting rates were obtained in all the crosses with this mandarin (Table 1). These results support the observations reported by Soares Filho et al. (2002), who also indicated that the 'Sunki' mandarin, as female parent, was related to high fruit setting rates. Furthermore, according to Soares Filho et al. (2013), the 'Sunki' mandarin produce progenies whose individuals show good vigor and relative uniformity, i.e., the hybrids generally resemble each other, a situation indicating a high degree of homozygosity present in this mandarin, more accentuated than that found in the overwhelming majority of citrus species.

With respect to the mortality rate (Table 1), among the crosses where the female parent was the 'Santa Cruz Rangpur' lime, the progeny SCRL $\times$ RSC performed the worst $(58 \%)$, in contrast to the cross SCRL $\times$ IDC $(43$ $\%)$. The 'Sunki of Florida' mandarin as female parent resulted in progenies whose mortality rates were much lower, ranging from $0 \%$ (SFM $\times$ BKTO) to $23 \%(\mathrm{SFM} \times$ THOM). This low number also featured in the geometric

Table 1 - Crosses, number of controlled pollinations within crosses (NP), number of fruits produced from these pollinations (NF), with respective fruit setting rates (FS), number of hybrid seedlings established in the field (NHF), mortality rate (MR) and geometric growth rate (GGR) of the hybrid seedlings in progenies from the first to the last year evaluated. Cruz das Almas, Bahia, Brazil.

\begin{tabular}{|c|c|c|c|c|c|c|c|c|c|c|}
\hline \multirow{2}{*}{ Crosses $^{1}$} & NP & $\mathrm{NF}$ & FS (\%) & \multicolumn{5}{|c|}{ NHF } & MR (\%) & GGR (\%) \\
\hline & \multicolumn{3}{|c|}{$2006-2007^{2}$} & $2008^{3}$ & 2010 & 2011 & 2013 & 2014 & 2014 & $2008-2014$ \\
\hline & \multicolumn{10}{|c|}{ 'Santa Cruz Rangpur' lime as female parent } \\
\hline SCRL $\times$ SFM & 27 & 13 & 48 & 49 & 36 & 33 & 24 & 24 & 51 & -11.0 \\
\hline SCRL $\times$ IDC & 42 & 14 & 33 & 30 & 21 & 21 & 19 & 17 & 43 & -9.0 \\
\hline$S C R L \times R S C$ & 20 & 7 & 35 & 26 & 17 & 16 & 15 & 11 & 58 & -13.0 \\
\hline \multirow[t]{2}{*}{ SCRL $\times$ THOM } & 36 & 9 & 25 & 27 & 19 & 16 & 16 & 12 & 56 & -12.0 \\
\hline & \multicolumn{10}{|c|}{ 'Sunki of Florida' mandarin as female parent } \\
\hline $\mathrm{SFM} \times \mathrm{SWC}$ & 68 & 48 & 71 & 172 & 162 & 157 & 142 & 136 & 21 & -3.8 \\
\hline $\mathrm{SFM} \times \mathrm{AGC}$ & 39 & 32 & 82 & 53 & 50 & 49 & 46 & 45 & 15 & -2.7 \\
\hline SFM $\times$ BKTO & 14 & 11 & 79 & 50 & 50 & 50 & 50 & 50 & 0 & 0.0 \\
\hline $\mathrm{SFM} \times \mathrm{THOM}$ & 23 & 14 & 61 & 35 & 32 & 30 & 28 & 27 & 23 & -4.2 \\
\hline $\mathrm{SFM} \times \mathrm{IDC}$ & 12 & 8 & 67 & 19 & 16 & 15 & 15 & 15 & 21 & -3.9 \\
\hline
\end{tabular}

${ }^{1}$ SCRL = 'Santa Cruz Rangpur' lime (Citrus limonia Osbeck); SFM = 'Sunki of Florida' mandarin [C. sunki (Hayata) hort. ex Tanaka]; IDC = 'Indio' citrandarin ['Sunki' mandarin $\times$ Poncirus tritoliata (L.) Raf. 'English' selection]; RSC = 'Riverside' citrandarin ('Sunki' mandarin $\times$ P. tritoliata 'English' selection); THOM = 'Thomasville' citrangequat \{'Oval' or 'Nagami' kumquat [Fortunella margarita (Lour.) Swingle] $\times$ 'Willits' citrange [C. sinensis (L.) Osbeck $\times P$.trifoliata]\}; SWC $=$ 'Swingle' citrumelo (C. paradisi Macfad. $\times$ P. trifoliata); AGC $=$ 'Argentina' citrange; BKTO $=P$. trifoliata 'Benecke' selection; 'Period when the pollinations and harvest of the fruits occurred; ${ }^{3}$ Year when the seedlings hybrids were planted in the field. 
growth rates, where the lowest value observed among the progenies of the 'Sunki of Florida'(-4.2 for SFM $\times$ THOM) was less than half the highest value observed for the progenies of the 'Santa Cruz Rangpur' lime (-9.0 for SCRL $\times$ IDC); the more negative the geometric growth rate, the higher the mortality rate.

The zero mortality rate found for the cross SFM $\times$ BKTO indicates its ability to generate individuals adapted to the biotic and abiotic stresses present in the environment studied. This environment is representative of the landscape unit of Coastal Tableland, which typically has soils that are poor in nutrients and low water retention capacity with cohesive horizons. These soil conditions limit the root depth (Pereira and Cestaro, 2012), and increase vulnerability to water stress during periods of high temperature and sparse rainfall, common in the region from Nov to Mar.

The visual vigor scores from the field evaluations between 2010 and 2014 are presented in Table 2. Due to plant mortality, the number of hybrids in the progenies declined over time (Table 1). Furthermore, in 2013 the region suffered a severe drought, which raised mortality and diminished the average vigor scores of the majority of the progenies (Table 2). The visual evaluations consider more vigorous plants to be those, regardless of size, which have good leaf development, without signs of nutritional deficiency or disease symptoms.

In the crosses where the 'Santa Cruz Rangpur' lime was the female parent, there were no significant differences in the means of visual vigor scores between the progenies (Table 2). With regard to the interval of variation (range of values), in general all the progenies of the female parent SCRL were between 1 (plants with poor vigor) and 3 (plants with good vigor), except in 2011 for the progenies SCRL $\times$ SFM and SCRL $\times$ IDC and 2014 for the progeny SCRL $\times$ THOM, where this interval was from 2 (plants with medium vigor) to 3. These results indicate that all the progenies of this 'Rangpur' lime variety showed significant variability between individuals, from weak to vigorous. The analysis of the Pearson skewness coefficient showed that, except for the progeny SCRL $\times$ IDC, the majority of the individuals obtained from the female parent the 'Santa Cruz Rangpur' lime had visual vigor superior to the averages of their respective progenies. This coefficient gives a notion of the distribution of the data of a determined variable in relation to its average: a negative coefficient indicates that most of the values are above the mean; this tendency is more significant the higher the negative value observed. The contrary applies to positive values (Bussab and Morettin, 2002).

Considering the female parent the 'Sunki of Florida', similar to the crosses having the 'Santa Cruz Rangpur' lime as the female parent, there were no significant differences in the means of visual vigor scores between the progenies (Table 2). As regards the ranges of variation, all the progenies were classified between 1 (plants with poor vigor) and 3 (plants with good vigor), except in 2011, when the progeny SFM $\times$ BKTO varied between 2 (plants with medium vigor) and 3 . This provides further evidence that all the progenies of this mandarin variety presented variability between individuals. However, in all years negative Pearson skewness coefficient values predominated, indicating that the visual vigor scores were concentrated above the mean and, consequently, these progenies can originate vigorous hybrids. An exception was progeny SFM $\times$ THOM in 2013 and 2014, where this coefficient was practically zero, meaning that the values of this variable were distributed symmetrically about the mean visual vigor score.

The 'Indio' citrandarin and the 'Thomasville' citrangequat presented variations in visual vigor as

Table 2 - Visual vigor scores of hybrid seedling trees within crosses, in the field, from 2010 to 2014. Cruz das Almas, Bahia, Brazil.

\begin{tabular}{|c|c|c|c|c|c|c|c|c|c|c|c|c|c|c|c|c|}
\hline \multirow{3}{*}{ Crosses $^{1}$} & \multicolumn{16}{|c|}{ Vigor $^{2}$} \\
\hline & \multicolumn{4}{|c|}{ Means } & \multicolumn{5}{|c|}{$\mathrm{R}^{3}$} & \multicolumn{3}{|c|}{$\mathrm{CV}^{4}$} & \multicolumn{4}{|c|}{$\mathrm{AS}^{5}$} \\
\hline & 2010 & 2011 & 2013 & 2014 & $\overline{\text { Means }}$ & 2010 & 2011 & 2013 & 2014 & 20102011 & 2013 & 2014 & 2010 & 2011 & 2013 & 2014 \\
\hline \multicolumn{17}{|c|}{ 'Santa Cruz Rangpur' lime as female parent } \\
\hline SCRL $\times$ SFM & 2.83 & 2.57 & 2.28 & 2.29 & $2.49 \mathrm{a}$ & $1.00-3.00$ & $2.00-3.00$ & $1.00-3.00$ & $1.00-3.00$ & 15.7819 .48 & 34.72 & 27.23 & -2.81 & -0.32 & -0.56 & -0.28 \\
\hline SCRL $\times$ IDC & 2.66 & 2.40 & 1.84 & 2.00 & $2.23 \mathrm{a}$ & $1.00-3.00$ & $2.00-3.00$ & $1.00-3.00$ & $1.00-3.00$ & 21.6520 .94 & 41.51 & 35.35 & -1.59 & 0.44 & 0.28 & 0.00 \\
\hline SCRL $\times$ RSC & 2.53 & 2.56 & 2.07 & 2.25 & $2.35 a$ & $1.00-3.00$ & $1.00-3.00$ & $1.00-3.00$ & $1.00-3.00$ & 28.3624 .55 & 41.52 & 38.49 & -1.26 & -1.18 & -0.16 & -0.56 \\
\hline SCRL $\times$ THOM & 2.21 & 2.26 & 2.36 & 2.61 & $2.36 \mathrm{a}$ & $1.00-3.00$ & $1.00-3.00$ & $1.00-3.00$ & $2.00-3.00$ & 38.6735 .24 & 35.71 & 19.36 & -0.44 & -0.55 & -0.83 & -0.54 \\
\hline \multicolumn{17}{|c|}{ 'Sunki of Florida' mandarin as female parent } \\
\hline SFM $\times$ SWC & 2.48 & 2.60 & 2.20 & 2.25 & $2.38 a$ & $1.00-3.00$ & $1.00-3.00$ & $1.00-3.00$ & $1.00-3.00$ & 31.5124 .95 & 34.74 & 32.50 & -1.08 & -1.39 & -0.38 & -0.43 \\
\hline $\mathrm{SFM} \times \mathrm{AGC}$ & 2.50 & 2.67 & 2.54 & 2.52 & $2.56 \mathrm{a}$ & $1.00-300$ & $1.00-3.00$ & $1.00-3.00$ & $1.00-3.00$ & 33.5623 .39 & 30.69 & 27.68 & -1.19 & -1.76 & -1.32 & -1.16 \\
\hline SFM $\times$ BKTO & 2.84 & 2.88 & 2.28 & 1.90 & $2.48 a$ & $1.00-3.00$ & $2.00-3.00$ & $1.00-3.00$ & $1.00-3.00$ & 19.3011 .40 & 34.36 & 40.14 & -3.19 & -2.41 & -0.55 & 0.17 \\
\hline $\mathrm{SFM} \times \mathrm{THOM}$ & 2.56 & 2.63 & 1.96 & 1.92 & $2.27 \mathrm{a}$ & $1.00-3.00$ & $1.00-3.00$ & $1.00-3.00$ & $1.00-3.00$ & 31.2525 .39 & 32.44 & 32.63 & -1.42 & -1.63 & 0.03 & 0.04 \\
\hline $\mathrm{SFM} \times \mathrm{IDC}$ & 2.13 & 2.60 & 2.40 & 2.13 & $2.32 \mathrm{a}$ & $1.00-3.00$ & $1.00-3.00$ & $1.00-3.00$ & $1.00-3.00$ & 46.4324 .32 & 23.35 & 34.84 & -0.30 & -1.41 & -0.55 & -0.22 \\
\hline
\end{tabular}


a function of the female parent used, with the 'Indio' performing better in crosses with the 'Sunki of Florida' mandarin, while the 'Thomasville' did better in crosses with the 'Santa Cruz Rangpur' lime. This situation shows that an individual can present variations in the behavior of the progenies obtained from it that depend on the parent with which it was hybridized. In the case of the crosses SCRL $\times$ THOM and SFM $\times$ IDC, the evidence indicates good specific combination capacity, as a consequence of genic and allelic interactions.

As expected, due to the high heterozygosity of citrus the hybrid seedlings within the progenies showed high variability in the traits plant height and trunk diameter. The height values of the trees obtained from the hybrid seedlings are shown in Table 3. During the entire period studied (2010 to 2014), the progeny SCRL $\times$ SFM presented the highest mean plant heights among the crosses where the female parent was the 'Santa Cruz Rangpur' lime. The relatively tall stature of the trees grown from the seedlings of this progeny can be confirmed by the range (R) of the height variable, whose upper limit was $4.10 \mathrm{~m}$. Moreover, in 2013 and 2014, this progeny presented negative coefficients of asymmetry for height, indicating that this cross can originate hybrids with plant heights, in general, greater than the mean.

With respect to the female parent the 'Sunki of Florida' mandarin, the progenies that stood out with the largest average heights were: SFM $\times$ BKTO $(\mathrm{R}$ : maximum of $4.50 \mathrm{~m}$ ), $\mathrm{SFM} \times \mathrm{AGC}(\mathrm{R}$ : maximum of $4.00 \mathrm{~m}$ ) and SFM $\times$ THOM (R: maximum of $4.00 \mathrm{~m}$ ). For these progenies, the negative Pearson skewness coefficient values predominated almost exclusively, indicating that these crossings have significant potential for generating vigorous individuals with above-average heights. In the hybridization SFM $\times$ BKTO, field ob- servations showed this progeny resulted in individuals that were, in general, relatively uniform in appearance. This behavior is related to the high level of homozygosity present in the parents of this cross, as verified by the high level of chromosome homomorphism that exists in both $C$. sunki (Morais et al., 2007) and P. trifoliata (Miranda et al., 1997), since there are indications of a direct relationship between levels of homozygosity and of chromosome homomorphism in citrus (Soares Filho et al., 2013).

With regard to the crosses having the 'Santa Cruz Rangpur' lime as female parent, in the trunk diameter measurements (Table 4), just as in the height measurements (Table 3), the progeny SCRL $\times$ SFM stood out registering the highest values in comparison with the other progenies, with a range that reached a maximum in 2014 of $14.40 \mathrm{~cm}$. The Pearson skewness coefficient values of the diameter measurement for this progeny were in general negative, meaning its offspring generally had trunk diameters greater than the mean. With respect to the female parent 'Sunki of Florida' mandarin, the progenies that stood out were SFM $\times$ BKTO, SFM $\times$ AGC and SFM $\times$ THOM, with greater mean diameter and negative Pearson skewness coefficients in 2014, indicating that in the last year of evaluation the majority of the individuals resulting from these crosses presented diameters greater than the mean. The maximum values for these crosses were $14.4 \mathrm{~cm}, 16.0 \mathrm{~cm}$ and $13.4 \mathrm{~cm}$, respectively.

The coefficients of variation of the progenies were classified as medium for the variables visual vigor, plant height and trunk diameter, respectively, in $89 \%, 86 \%$ and $75 \%$ of the cases following the method proposed by Garcia (1989). According to Cargnelutti Filho and Storck (2007), the lower the estimate of the $\mathrm{CV}$, the greater the precision of the experiment, and vice versa.

Table 3 - Height of hybrid seedling trees within the crosses, in the field, from 2010 to 2014. Cruz das Almas, Bahia, Brazil.

\begin{tabular}{|c|c|c|c|c|c|c|c|c|c|c|c|}
\hline \multicolumn{12}{|c|}{ Height (m) } \\
\hline \multirow[t]{2}{*}{ Crosses $^{1}$} & \multicolumn{4}{|c|}{ Means } & \multirow[b]{2}{*}{ Means } & \multicolumn{4}{|c|}{$\mathrm{R}^{2}$} & $\mathrm{CV}^{3}$ & $\mathrm{AS}^{4}$ \\
\hline & 2010 & 2011 & 2013 & 2014 & & 2010 & 2011 & 2013 & 2014 & $\begin{array}{llll}2010 & 2011 & 2013 & 2014 \\
\end{array}$ & 2010201120132014 \\
\hline \multicolumn{12}{|c|}{ 'Santa Cruz Rangpur' lime as female parent } \\
\hline SCRL $\times$ SFM & 0.89 & 1.58 & 2.57 & 3.18 & $2.06 \mathrm{~b}$ & $0.20-1.55$ & $0.95-2.45$ & $0.90-3.90$ & $0.95-4.10$ & 35.5626 .6230 .8426 .77 & $0.05 \quad 0.19-0.46-1.07$ \\
\hline SCRL $\times$ IDC & 0.73 & 1.18 & 1.71 & 2.28 & $1.48 \mathrm{~d}$ & $0.25-1.55$ & $0.30-1.85$ & $0.90-2.70$ & $0.95-3.40$ & 38.0935 .6130 .0226 .93 & $\begin{array}{llll}1.07 & -0.30 & 0.38 & -0.24\end{array}$ \\
\hline $\mathrm{SCRL} \times \mathrm{RSC}$ & 0.63 & 1.22 & 1.74 & 2.32 & $1.48 \mathrm{~d}$ & $0.30-1.00$ & $0.30-2.40$ & $0.50-3.20$ & $1.20-4.40$ & $\begin{array}{llll}34.17 & 42.67 & 45.30 & 44.4\end{array}$ & $\begin{array}{llll}-0.30 & 0.58 & 0.54 & 0.75\end{array}$ \\
\hline SCRL $\times$ THOM & 0.63 & 1.10 & 1.60 & 2.39 & $1.43 \mathrm{~d}$ & $0.15-1.15$ & $0.30-2.20$ & $0.50-2.60$ & $0.65-3.50$ & $52.4055 .91 \quad 45.4139 .63$ & $\begin{array}{llll}0.28 & 0.40 & -0.15 & -0.77\end{array}$ \\
\hline \multicolumn{12}{|c|}{ 'Sunki of Florida' mandarin as female parent } \\
\hline $\mathrm{SFM} \times \mathrm{SWC}$ & 0.88 & 1.46 & 2.30 & 2.85 & $1.87 \mathrm{~b}$ & $0.15-1.95$ & $0.20-2.40$ & $0.25-3.80$ & $0.30-4.30$ & $34.9134 .03 \quad 32.66 \quad 31.17$ & $\begin{array}{llll}0.40 & -0.31 & -0.61 & -0.70\end{array}$ \\
\hline $\mathrm{SFM} \times \mathrm{AGC}$ & 1.00 & 1.57 & 2.48 & 2.91 & $1.99 \mathrm{~b}$ & $0.10-2.00$ & $0.45-2.70$ & $0.70-4.00$ & $0.70-4.00$ & $40.28 \quad 42.7739 .16 \quad 35.56$ & $\begin{array}{llll}0.18 & -0.14 & -0.40 & -0.87\end{array}$ \\
\hline SFM $\times$ BKTO & 1.43 & 2.05 & 3.06 & 3.54 & $2.52 \mathrm{a}$ & $0.60-2.20$ & $0.80-2.70$ & $1.60-4.10$ & $1.40-4.50$ & $28.1521 .6321 .73 \quad 21.82$ & $\begin{array}{llll}-0.13 & -0.73 & -0.68 & -0.94\end{array}$ \\
\hline $\mathrm{SFM} \times \mathrm{THOM}$ & 0.88 & 1.45 & 2.45 & 2.93 & $1.93 \mathrm{~b}$ & $0.30-1.45$ & $0.35-2.15$ & $0.95-3.40$ & $1.10-4.00$ & $\begin{array}{llll}36.07 & 30.50 & 25.40 & 28.77\end{array}$ & $\begin{array}{llll}-0.35 & -0.84 & -0.90 & -1.04\end{array}$ \\
\hline $\mathrm{SFM} \times \mathrm{IDC}$ & 0.72 & 1.25 & 2.06 & 2.76 & $1.70 \mathrm{c}$ & $0.30-1.40$ & $0.55-2.00$ & $1.30-3.00$ & $1.80-3.80$ & $\begin{array}{llll}40.54 & 32.84 & 29.63 & 23.43\end{array}$ & $\begin{array}{llll}1.01 & 0.04 & 0.19 & -0.70\end{array}$ \\
\hline
\end{tabular}


Table 4 - Trunk diameter of hybrid seedling trees within the crosses, in the field, from 2010 to 2014. Cruz das Almas, Bahia, Brazil.

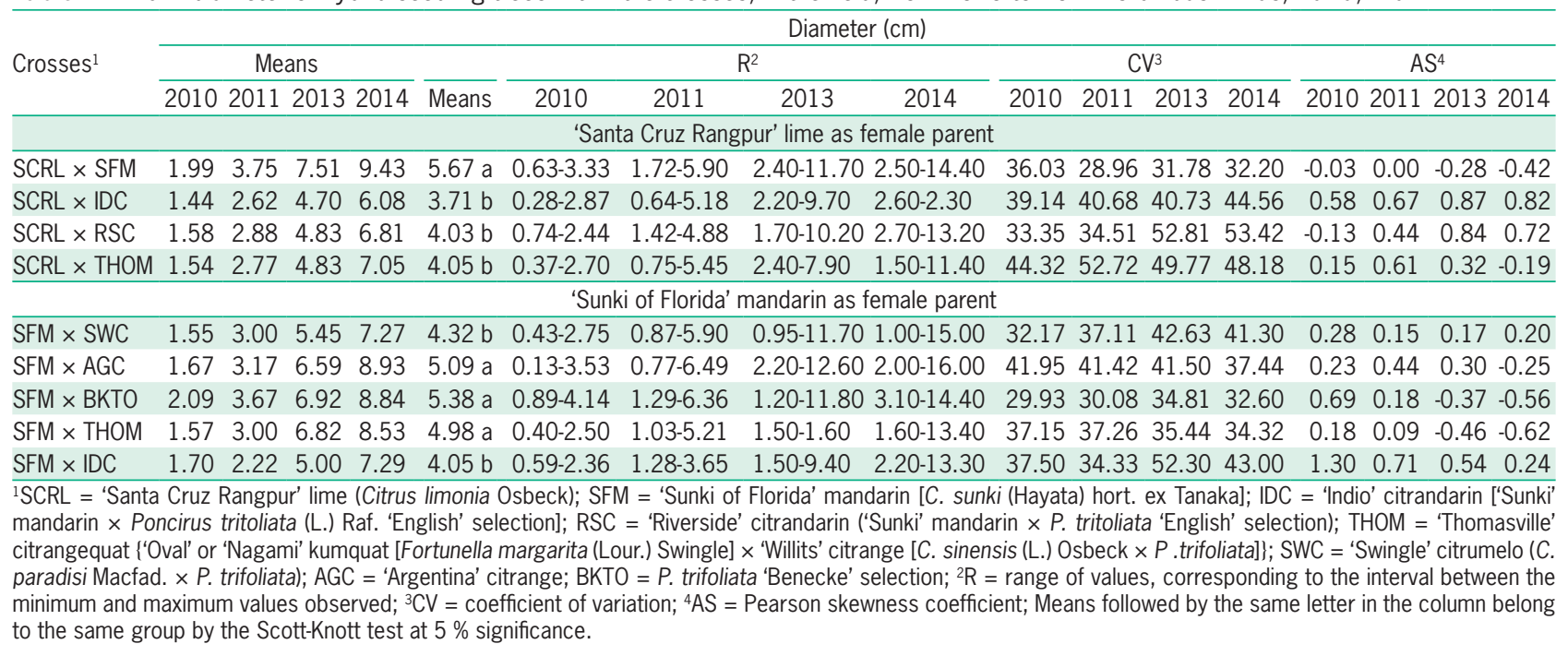

In the evaluations of vigor (related to plant height and trunk diameter), the 'Indio' citrandarin and the 'Thomasville' citrangequat, as male parents, presented variations in the crosses with the 'Sunki of Florida' mandarin and the 'Santa Cruz Rangpur' lime, indicating better behavior of the 'Indio' and the 'Thomasville' with the 'Sunki of Florida'. This observation, as seen previously, indicates that an individual can show variations in the behavior of the progenies obtained from it, depending on the other parent forming the hybrid.

The 'Sunki of Florida' mandarin was superior to the 'Santa Cruz Rangpur' lime as a female parent in all the evaluations carried out. Furthermore, this mandarin variety also stood out as the male parent in crosses with the 'Santa Cruz Rangpur' lime, producing a higher fruit setting rate generating more vigorous hybrids. Similar results were reported by Soares Filho et al. (2014). This behavior suggests the presence of a high frequency of favorable alleles in the majority of genetic loci of the 'Sunki' mandarin, enabling the formation of gametes, both male and female, that lead to high fruit setting rates in the crosses carried out, and generate a larger number of promising hybrids.

\section{Conclusion}

The crosses SCRL $\times$ SFM, SFM $\times$ BKTO, SFM $\times$ AGC and SFM $\times$ THOM had high potential for generating vigorous hybrids that are adapted to the landscape unit of Coastal Tableland, where this study was conducted. SFM $\times$ BKTO stood out for its high fruit setting rate (nearly $80 \%$ ) and zero mortality.

In the crosses, the good behavior of the 'Sunki of Florida' mandarin, both as female and male parent, suggests the presence of a high frequency of favorable alleles in the majority of its genetic loci, as well as good general combining ability in hybridizations, as a reflection of the genetic additive effect.

\section{Acknowledgments}

We express thanks to the Embrapa Cassava \& Fruits servers Magno Guimarães Santos, for assistance in the obtaining and analyzing of data, and Getúlio de Souza Vieira and Antônio Santana da Silva, for performing the pollinations and managing the hybrid populations, respectively, essential to the materialization of this study.

\section{References}

Bussab, W.O.; Morettin, P.A. 2002. Basic Statistics = Estatística Básica. 5ed. Saraiva, São Paulo, SP, Brazil (in Portuguese).

Cargnelutti Filho, A.; Storck, L. 2007. Evaluation statistics of the experimental precision in corn cultivar trials. Pesquisa Agropecuária Brasileira 42: 17-24 (in Portuguese, with abstract in English).

Food and Agriculture Organization [FAO]. 2016. Agricultural statistics database. World Agricultural Information Center. Available at: http:// faostat.fao.org/site/567/default.aspx\#ancor [Accessed Mar 09, 2016]

Fundecitrus. 2014. Citrus sudden death - CSD = Morte súbita dos citros. Available at: http://www.fundecitrus.com.br/doencas/ msc/11 [Accessed Nov 25, 2014] (in Portuguese).

Garcia, C.H. 1989. Tables for Coefficients of Variation Classification = Tabelas de Classificação de Coeficientes de Variação. IPEF, Piracicaba, SP, Brazil (Circular Técnica, 171) (in Portuguese).

Instituto Brasileiro de Geografia e Estatística [IBGE]. 2004. Brazil's population projection by age and sex for 1980-2050 period $=$ Projeção populacional do Brasil por idade e sexo para o período 1980-2050. Available at: http: https://www.ibge.gov. br/home/estatistica/populacao/projecao_da_populacao/2004/ metodologia.pdf [Accessed Jul 12, 2017] (in Portuguese).

Khan, I.A.; Kender, W.J. 2007. Citrus breeding: introduction and objectives. p. 1-8. In: Khan, I.A., ed. Citrus genetics, breeding and biotechnology. CABI, Wallingford, UK. 
Miranda, M.; Ikeda, F.; Endo, T.; Moriguchi, T.; Omura, M. 1997. Comparative analysis on the distribution of heterochromatin in Citrus, Poncirus and Fortunella chromosomes. Chromosome Research 5: 86-92.

Morais, A.P.; Lemos, R.R.; Brasileiro-Vidal, A.C.; Soares Filho, W.S.; Guerra, M. 2007. Chromosomal markers distinguish hybrids and non-hybrid accessions of mandarin. Cytogenetic and Genome Research 119: 275-281.

Oliveira, A.C.; Garcia, A.N.; Cristofane, M.; Machado, M.A. 2002. Identification of citrus hybrids through the combination of leaf apex morphology and SSR markers. Euphytica 128: 397403.

Pereira, V.H.C.; Cestaro, L.A.A. 2012. The coastal tableland geoenvironmental unit and the county planning: the Senator Georgino Avelino/RN case. Revista Geonorte 3: 390-401/in Portuguese, with abstract in English).

Scott, A.; Knott, M. 1974. Cluster-analysis method for grouping means in analysis of variance. Biometrics 30: 507-512.

Soares Filho, W.S.; Medrado, A.C.M.; Cunha, M.A.P.; Cunha Sobrinho, A.P.; Passos, O.S. 2002. Frequency of citrus hybrids from controlled crossings: seed germination in seedbeds versus in vitro embryo cultivation. Pesquisa Agropecuária Brasileira 37: 981-988 (in Portuguese, with abstract in English).
Soares Filho, W.S.; Cunha Sobrinho, A.P.; Passos, O.S.; Souza, A.S. 2013. Genetic breeding = Melhoramento genético. p. 61102. In: Cunha Sobrinho, A.P.; Magalhães, A.F.J.; Souza, A.S.; Passos, O.S.; Soares Filho, W.S., eds. Citrus culture $=$ Cultura dos citros. Embrapa, Brasília, DF, Brazil (in Portuguese).

Soares Filho, W.S.; Souza, U.; Ledo, C.A.S.; Santana, L.G.L.; Passos, O.S. 2014. Polyembryony and potential of hybrid production in citrus. Revista Brasileira de Fruticultura 36: 950956 (in Portuguese, with abstract in English).

Soost, R.K.; Cameron, J.W. 1975. Citrus. p. 507-540. In: Janick, J.; Moore, J.N., eds. Advances in fruit breeding. Purdue University Press, West Lafaiette, IN, USA.

Zekri, M. 2011. Factors affecting citrus production and quality. Citrus Industry. Available at: http://www.crec.ifas.ufl.edu/ extension/trade_journals/2011/2011_dec_factors_citrus.pdf [Accessed Apr 22, 2016] 